\title{
WILLINGNESS TO PAY WARUNG MAKAN TERHADAP TPS 3R DI DESA BABAKAN KABUPATEN BOGOR
}

\author{
Ni Putu Manacika Manupada ${ }^{1 *}$, Ahyar Ismail ${ }^{2)}$, Meti Ekayani ${ }^{3)}$ \\ ${ }^{1)}$ Pascasarjana Pengelolaan Sumberdaya Alam dan Lingkungan IPB \\ ${ }^{2)}$ Ekonomi Sumberdaya dan Lingkungan Institut Pertanian Bogor \\ ${ }^{3)}$ Ekonomi Sumberdaya dan Lingkungan Institut Pertanian Bogor \\ *Email: manupada_1801@apps.ipb.ac.id
}

\section{ABSTRACT \\ SMALL-SCALE RESTAURANTS' WILLINGNESS TO PAY FOR TPS 3R IN BABAKAN, BOGOR REGENCY}

Babakan is one of administrative villages in Bogor Regency where Institut Pertanian Bogor (IPB) is located. IPB has given social and economic impacts in Babakan that many smallscalled business developed and small-scalled restaurant has the most participators. These smallscale restaurants generate waste everyday and the waste is still managed with end of pipe practice where waste was hauled from collection point to disposal site without any intermediate treatment. Waste management problem is a complex work to do and it needs integration from goverment, private, and community. Community based waste management with $3 \mathrm{R}$ (reduce, reuse, recycle) approach should be proposed to reduce waste at source because it can not only reduce waste that is hauled to disposal site, but also reduce transportation cost which has the largest share of waste management's total cost.The Ministry of Public Works and Public Housing (KPUPR) targeted 100\% for Indonesia's waste management services in 2019 and 3R Solid Waste Treatment Facilities (TPS 3R) provision is one of their physical programs.3R Solid Waste Treatment Facilities (TPS 3R) is a facility that focused on reducing, reusing, and recycling waste at source comunally involved active roles from community and goverment. The objectives of this study are (1) Examining level of participation of small-scale restaurant owners if TPS 3R is built and implemented in Babakan. (2) Estimating Willingness to Pay (WTP) of small-scale restaurans owners to TPS $3 \mathrm{R}$ implementation planning. The results showed most of small-scale restaurant owners are willing to participate in both sorting waste at source and paying TPS $3 R$ service rate if TPS $3 R$ is being implemented in Babakan even though there are potential free riders. Average WTP values for TPS 3R is Rp 32,250/month and it is higher than existing rate of waste collection service, which shows small-scale restaurant owners have preference for TPS 3R in Babakan.

Keywords: small-scaled restaurants, TPS 3R, waste management, willingness to pay

\section{PENDAHULUAN}

Masalah lingkungan merupakan masalah global. Salah satu masalah lingkungan yang memerlukan perhatian khusus, baik di negara maju maupun di negara berkembang adalah masalah sampah dan pengelolaannya. Peningkatan jumlah timbulan sampah berbanding lurus dengan peningkatan jumlah penduduk. Semakin besar jumlah penduduk suatu wilayah, maka semakin bervariasi jenis dan karakteristik sampah yang dihasilkan serta semakin besar jumlah dan ragam sampah yang ditimbulkan akibat adanya perubahan pola hidup yang semakin konsumtif (Martinawati et al.,2016).

Pengelolaan sampah perkotaan di Indonesia sebagian besar masih menggunakan sistem kumpul-angkut-buang dan masih terkonsentrasi di Tempat Pemrosesan Akhir (TPA), termasuk di Kabupaten Bogor yang merupakan salah satu daerah penyangga ibu kota negara. Berdasarkan rilis Dinas Komunikasi dan Informatika (Diskominfo) Kabupaten Bogor pada tahun 2019, hanya sekitar 700 ton sampah yang dapat diangkut oleh truk sampah milik Dinas Lingkungan Hidup (DLH) ke TPA Galuga dari 2,800 ton 
sampah rumah tangga yang dihasilkan setiap harinya. Hal ini dikarenakan Kabupaten Bogor selain memiliki wilayah yang luas,juga jumlah penduduk yang besar sehingga tidak semua sampah yang dihasilkan oleh masyarakat dapat diangkut dan dikelola oleh pemerintah.

Pola pengelolaan sampahyang masih terpusat pada pendekatan akhir di TPA (end of pipe) harus ditinggalkan dan diperbaharui karena sudah tidak efektif dan hanya sekedar melakukan pemindahan masalah sampah dari sumbernya ke TPA (Rahman, 2013). Kondisi ini dapat meningkatkan beban dan juga mengurangi umur penggunaan TPA (Suyanto et al., 2015) karena lahan yang digunakan sebagai TPA tidak mampu lagi menampung sampah yang sudah ada (Widiarti, 2012) dan daya dukung untuk mengasimilasi sampahnya pun terbatas (Subhardarsini, 2015). Pola pengelolaan sampah dengan pendekatan reduce, reuse, recycle (3R) yang berbasis masyarakat harus didorong agar sampah dapat terkelola dari sumbernya. Undang-Undang No.8 Tahun 2008 tentang Pengelolaan Sampah dan Peraturan Pemerintah No.81 Tahun 2012 tentang Pengelolaan Sampah Rumah Tangga dan Sampah Sejenis Sampah Rumah Tangga sudah mengamanatkan bahwa pengurangan sampah sejak dari sumbernya adalah tanggung jawab seluruh pihak, yaitu pemerintah dan masyarakat. Namun, kondisi dan fasilitas pemilahan dan pengurangan sampah dari sumbernya yang ada saat ini masih kurang memadai sehingga pengelolaan sampah sejak dari sumbernya masih menjadi kendala untuk dilakukan.

Desa Babakan adalah salah satu desa di Kabupaten Bogor, dimana Institut Pertanian Bogor (IPB), yang merupakan salah satu perguruan tinggi negeri di Indonesia berlokasi. Keberadaan IPB memberikan dampak ekonomi dan sosial bagi masyarakat di sekitar Desa Babakan. Pelaku usaha pun timbul dan akhirnya menjamur di Desa Babakan untuk memenuhi kebutuhan seharihari para civitas kampus IPB dan usaha warung makan adalah usaha yang paling banyak diminati. Warung-warung makan di Desa Babakan menghasilkan sampah setiap harinya dan sampah yang dihasilkan ini masih dikelola dengan sistem kumpul-angkut-buang.
Sampah warung makan dibawah manajemen IPB dikelola unit kebersihan dari kampus dan sampah warung makan diluar manajemen kampus dikelola unit kebersihan dari RT/RW setempat.

Petugas sampah mengumpulkan sampah dari warung makan kemudian diangkut dan dikumpulkan ke Tempat Penampungan Sementara (TPS) terdekat, yaitu TPS dalam kampus IPB untuk sampah dari warung makan dibawah manajemen IPB dan TPS Sawah Baru untuk sampah dari warung makan diluar manajemen IPB. Sampah yang tertampung di TPS dalam kampus IPB diangkut ke TPA Cikabayan, sedangkan yang di TPS Sawah Baru diangkut ke TPA Galuga oleh petugas dari DLH Pemerintah Kabupaten (Pemkab) Bogor dan Kota (Pemkot) Bogor. Perilaku (behavior) produsen warung makan yang belum memilah sampah secara mandiri juga menghambat upaya pengurangan dan penanganan sampah di Desa Babakan, meskipun Peraturan Daerah (Perda) Kabupaten Bogor No.2 Tahun 2014 tentang Pengelolaan Sampah telah mengamanatkan untuk pelaku usaha wajib melakukan pengurangan produksi sampah dan penanganan sampah yang berwawasan lingkungan. Pola pengelolaan sampah di Desa Babakan yang juga masih terkonsentrasi di TPA ini perlu diarahkan kepada pengelolaan sampah berbasis masyarakat dengan pendekatan 3R (reduce, reuse, recycle) agar sampah dapat terkelola dari sumbernya karena pada dasarnya, menurut Anjani (2011), pengelolaan sampah merupakan pekerjaan rumah yang kompleks sehingga integrasi dari semua pihak, baik pemerintah, swasta, dan masyarakat diperlukan.

Pemerintah pusat melalui Direktorat Jendral (Dirjen) Cipta Karya Kementerian Pekerjaan Umum dan Perumahan Rakyat (KPUPR) menginisiasi program pengembangan sistem pengelolaan pengembangan sistem pengelolaan persampahan dengan target akses pelayanan pengelolaan sampah $100 \%$ pada tahun 2019 . Terdapat dua jenis program yang dijalankan untuk mencapai target ini, yaitu program fisik dan program non-fisik. Penyelenggaraan Tempat Pengolahan Sampah Reduce-ReuseRecycle (TPS 3R) merupakan salah satu 
bagian dari program fisik yang diinisiasi dan dijalankan untuk mengurangi dan mengelola sampah pada skala komunal atau kawasan dari sumbernya dengan melibatkan masyarakat dan pemerintah. TPS 3R diselenggarakan dengan menekankan untuk mengurangi, memanfaatkan, dan mengolah sampah dari sumbernya (KPUPR, 2017). Rangkaian pengelolaan sampah terdiri dari beberapa subsistem, yaitu pewadahan, pengumpulan, pengangkutan, pengolahan, serta pemrosesan akhir, dan TPS 3R merupakan bagian dari subsistem pengolahan.

Pengelolaan sampah dengan proses $3 \mathrm{R}$ di sumber selain dapat mengurangi beban TPA juga dapat menghemat biaya transportasi pengangkutan dari TPS ke TPA karena menurut Rahim et al. (2012), komponen biaya terbesar pada layanan pengelolaan sampah perkotaan di sebagian besarkota-kota di Indonesia saat ini adalah biaya pengangkutan, yaitu 35.5\%-76.3\%. Maka dari itu, TPS 3R dapat menjadi alternatif pengelolaan sampah berbasis masyarakat di Desa Babakan agar masalah sampah dapat ditangani dari sumbernya untuk mengurangi beban sampah di TPA.Maka dari itu, tujuan dilakukannya penelitian ini adalah (1) Mengkaji tingkat partisipasi produsen warung makan jika TPS 3R diselenggarakan di Desa Babakan. (2) Mengestimasi nilai Willingness to Pay (WTP) produsen warung makan terhadap rencana penyelenggaraan TPS 3R di Desa Babakan.

\section{METODOLOGI}

\subsection{Lokasi Penelitian}

Penelitian ini telah dilaksanakan di warung-warung makan yang berada sepanjang Jalan Babakan Raya dan Babakan Tengah $( \pm 800 \quad \mathrm{~m})$, Desa Babakan, Kecamatan Dramaga, Kabupaten Bogor, dengan panjang jalan $800 \mathrm{~m}$. Warung makan yang dikaji adalah warung makan yang mempunyai bentuk bangunan permanen, berada di sepanjang Jalan Babakan Raya dan Babakan Tengah, dan yang masuk $100 \mathrm{~m}$ ke dalam gang karena warung makan dengan bangunan permanen membayar retribusi sampah ke RT/RW setempat. Lokasi penelitian ditentukan secara sengaja (purposive) yaitu lokasi ditentukan dengan pertimbangan tertentu (Sugiyono, 2013) dimana lokasi memiliki tingkat kepadatan warung makan tertinggi di Desa Babakan.

\subsection{Metode Pengambilan Sampel dan Data}

Populasi dalam kajian ini adalah Warung Tegal (Warteg) dan warung dengan sistem menu pilihan konsumen(A la Carte) karena Warteg dan A la Carte merupakan jenis warung makan dengan jumlah terbanyak dibandingkan dengan warung makan jenis lainnya di Desa Babakan. Jumlah Warteg sebanyak 15 unit dan A la Carte 18 unit sehingga populasi warung makan dalam kajian ini adalah 33 unit warung makan. Sebanyak 11 Warteg dan 13 A la Carte menjadi responden penelitian sehingga jumlah sampel adalah 24 warung makan (Tabel 1).

Tabel 1. Populasi dan Sampel Responden Warung Makan

\begin{tabular}{clcc}
\hline No & \multicolumn{1}{c}{$\begin{array}{c}\text { Jenis } \\
\text { warung } \\
\text { makan }\end{array}$} & $\begin{array}{c}\text { Populasi } \\
(\mathrm{N})\end{array}$ & Sampel (n) \\
\hline 1 & Warung & 15 & 11 \\
2 & Tegal & 18 & 13 \\
& A la Carte & & \\
\hline & Total & 33 & 24 \\
\hline
\end{tabular}

Data primer dalam penelitian ini diperoleh secara langsung dari pengamatan secara langsung di lapangan dan wawancara mendalam (indepth interview) dengan responden melalui kuesioner yang telah disusun oleh peneliti, disesuaikan dengan komponen analisis dan tujuan penelitian.

\subsection{Metode Analisis Data}

\subsubsection{Kajian Tingkat Partisipasi Produsen Warung Makan}

Tingkat partisipasi produsen warung makan terhadap rencana penyelenggaraan TPS 3R di Desa Babakan dikaji dengan analisis deskriptif kualitatif untuk menggambarkan kondisi secara apa adanya tanpa memberikan perlakuan pada variabelvariabel yang diteliti (Sukmadinata, 2011). 
Data tingkat partisipasi produsen warung makan yang telah diperoleh disajikan dengan diagram, kemudian diinterpretasikan. Indikator yang digunakan untuk mengidentifikasi tingkat partisipasi produsen warung makan yaitu (1) kesediaan berpartisipasi untuk memilah sampah dari sumbernya saja; (2) kesediaan berpartisipasi untuk membayar retribusi saja; (3) kesediaan berpartisipasi untuk memilah sampah dan membayar retribusi; dan (4) tidak bersedia berpartispasi untuk keduanya

\subsubsection{Analisis Willingness to Pay Produsen Warung Makan}

Besarnya nilai kesediaan pengelola warung makan untuk membayar (WTP) retribusi penyelenggaraan TPS 3R didapatkan dengan menggunakan pendekatan Contingent Valuation Method (CVM). CVM adalah metode penilaian ekonomi melalui pertanyaan langsung kesediaan seseorang untuk membayar atau yang biasa disebut Willingness to Pay (WTP), yang dimana nilai WTP yang diduga didapatkan melalui tawaran pilihan yang setiap pilihannya memiliki variabel karakteristik harga atau biaya (Fauzi, 2014). Nilai WTP ditentukan melalui 3 tahap (Fauzi, 2006), yaitu (1) melakukan konstruksi skenario pasar hipotetik; (2) mendapatkan besarnya penawaran nilai WTP; dan (3) mengestimasirataan nilai WTP (EWTP). Tahapan untuk menentukan nilai WTP dijabarkan sebagai berikut:

\section{A. Konstruksi Pasar Hipotetik}

Pengelolaan sampah yang berjalan di Desa Babakan saat ini masih dengan sistem kumpulangkut-buang, dimana sampah yang dikumpulkan oleh petugas kebersihan dari warung makan diangkut ke TPS, kemudian dibuang ke TPA tanpa adanya proses pengolahan sebelumnya. Diperlukan sistem pengelolaan sampah berbasis masyarakat dengan pendekatan reduce (mengurangi), reuse (menggunakan kembali), sertarecycle (daur ulang) atau 3R untuk memperbaiki sistem pengelolaan sampah yang ada saat ini.

Pemerintah pusat melalui Dirjen Cipta Karya KPUPR memiliki program fisik untuk memperbaiki sistem pengelolaan sampah agar dapat terkelola dari sumbernya, yaitu dengan menyelenggaraan TPS 3R, dimana pola pendekatan pengelolaan sampah dilakukan pada skala komunal (area pemukiman, komersial, wisata, perkantoran, pendidikan, dan lainnya) yang diarahkan pada konsep 3R dengan melibatkan peran aktif pemerintah dan masyarakat atau berbasis masyarakat (KPUPR, 2017). Tujuan utama penyelenggaraan TPS $3 R$ adalah untuk melakukan pengurangan jumlah perbaikan karakteristik sampah yang akan diolah di TPA agar kebutuhan lahan yang semakin kritis terjamin untuk penyediaan TPA sampah pada perkotaan di Indonesia. Manfaat yang dapat dirasakan dengan adanya TPS 3R adalah lingkungan akan menjadi lebih bersih dan sehat karena sampah yang biasanya ditampung begitu saja di TPS nantinya akan diolah dan dimanfaatkan terlebih dahulu sehingga sampah yang masuk ke TPA hanyalah residunya saja. Maka dari itu, partisipasi masyarakat (yang dalam hal ini adalah pengelola warung makan) diperlukan guna terselenggaranya TPS $3 R$ di Desa Babakan.

\section{B. Penawaran Nilai WTP}

Metode permainan lelang (bidding game) digunakan untuk mendapatkan penawaran nilai WTP responden, dimana responden diberi pertanyaan secara berulang-ulang apakah mereka ingin membayar dengan sejumlah tertentu dan nilai ini dapat dinaikkan atau diturunkan (Fauzi, 2006) dan nilai WTP didapatkan setelah proses bidding selesai. Harga dasar penawaran WTP responden sebesar Rp 10,000.00/bulan.

\section{Rataan Nilai WTP}

Nilai WTP yang telah diperoleh kemudian dirata-ratakan dengan rumus perhitungan sebagai berikut:

$E W T P=\frac{\sum_{i=1}^{n} W i}{n}$

dimana:

EWTP $=$ Dugaan nilai rataan WTP

$W i=$ Nilai WTP ke-i (Rp)

$\mathrm{n}=$ Jumlah responden (orang)

$\mathrm{i}=$ Responden ke-i yang bersedia membayar retribusi terhadap rencana penyelenggaraan TPS 3R di Desa Babakan 


\section{HASIL DAN PEMBAHASAN}

\subsection{Gambaran Umum}

\subsubsection{Deskripsi Lokasi}

Desa Babakan berada di wilayah Kecamatan Dramaga, Kabupaten Bogor, Jawa Barat. Desa Babakan memiliki luas wilayah \pm 334.384 Ha, terdiri dari 4 dusun, $9 \mathrm{RW}$, dan 35 RT. Jarak Desa Babakan dari pusat pemerintahan kecamatan adalah $1,5 \mathrm{~km}$, dari pusat pemerintahan kabupaten $25 \mathrm{~km}$, dari pusat pemerintahan provinsi $129 \mathrm{~km}$, dan dari pusat ibu kota negara adalah $60 \mathrm{~km}$.

Berikut merupakan batas-batas Desa Babakan secara administratif:

Sebelah Utara : Desa Cikarawang

Sebelah Timur: Kelurahan Balumbang Jaya

Sebelah Selatan: Desa Dramaga

Sebelah Barat : Desa Cibanteng, Kecamatan Ciampea.

\subsubsection{Karakteristik Warung Makan}

Warung Tegal merupakan salah satu jenis warung nasi dimana makanan disajikan dan konsumen dilayani dengan pendekatan karakter masyarakat daerah Tegal (Khamdevi dan Nasution, 2014). Ciri khas Warung Tegal adalah penataan yang memberi kesan sederhana, menu yang cukup lengkap, serta harga jual pelayanan dan makanannya yang relatif murah dan terjangkau masyarakat kelas bawah (Juanda, 2004). Pada umumnya, Warung Tegal berada di kawasan padat penduduk seperti kawasan industri dan kawasan pendidikan (Putra dan Putro, 2015). Warung Tegal memiliki cara penyajian yang mirip dengan Warung Padang, dimana konsumen yang datang memilih dan memesan lauk dan sayur yang tersedia pada display warung. Porsi nasi sudah ditentukan oleh pemilik Warung Tegal, namun konsumen dapat memilih porsi satu atau setengah, yang dimana memiliki takaran yang berbeda.

Warung makan dengan sistem menu pilihan konsumen adalah $A$ la Carte dan menu A la Carte adalah susunan menu dimana setiap makanan dicantumkan pada daftar menu beserta harganya tersendiri (Suryantika dan Dewi, 2012). Selain itu, ciri khas dari $A$ la Carte yang berada di Desa Babakan adalah menu dimasak setelah pesanan dari konsumen.

\subsubsection{Tempat Pengolahan Sampah Reduce- Reuse-Recycle (TPS 3R)}

Alternatif pengelolaan sampah perlu diarahkan dari paradigma lama yaitu sistem kumpul-angkut-buang menjadi sistem pengelolaan sampah berbasis masyarakat yang mengurangi dan menangani sampah sejak di sumbernya dengan konsep 3R, sesuai dengan amanat PP No.81 Tahun 2012 tentang Pengelolaan Sampah Rumah Tangga dan Sampah Sejenis Sampah Rumah Tangga. Maka dari itu, pembangunan dan penyelenggaraan TPS 3R di Desa Babakan merupakan salah satu alternatif pengelolaan sampah yang dapat ditawarkan untuk mengatasi masalah sampah dan memenuhi target pelayanan pengelolaan sampah $100 \%$ di tahun 2019 yang dicanangkan oleh pemerintah.

Tempat Pengolahan Sampah dengan prinsip Reduce-Reuse-Recycle (TPS 3R) adalah infrastruktur pengolahan sampah yang dimana cara pengurangan, pemanfaatan, dan pengolahan sejak dari sumbernya pada skala komunal (area pemukiman, komersial, perkantoran, pendidikan, wisata, dan lainlainnya) lebih ditekankan dengan melibatkan peran aktif pemerintah dan masyarakat. Tujuan dari penyelenggaraan program TPS 3R adalah (KPUPR, 2017):

1 Peningkatkan komitmen pemerintah daerah (pemda) dalam penyelenggaraan TPS 3R.

2 Peningkatan masyarakat dalam memahami dan menyadari akan pengelolaan sampah dan perilaku hidup bersih dan sehat (PHBS) masyarakat.

3 Penyediaan prasarana dan sarana pengelolaan sampah yang lebih baik dan memiliki wawasan lingkungan yang disesuaikan kebutuhan peningkatan kualitas sumberdaya air dan lingkungan.

4 Pengurangan beban pemrosesan sampah di TPA melalui pengurangan sampah sejak dari sumbernya.

5 Peningkatan kapasitas kelembagaan masyarakat. 
Konsep utama pengolahan sampah pada TPS 3R adalah pengurangan kuantitas dan perbaikan karakteristik sampah yang akan diproses lebih lanjut di TPA dan tidak berperan sebagai pabrik yang menghasilkan suatu produk, seperti pabrik kompos, gas bio, dan sampah daur ulang.

Rencana pembangunan TPS 3R di desa sekitar kampus IPB mengacu pada persayaratan teknis dalam Peraturan Menteri Pekerjaan Umum No.3 Tahun 2013 tentang Penyelenggaraan Prasarana dan Sarana Persampahan dan Penanganan Sampah Rumah Tangga dan Sampah Sejenis Sampah Rumah Tangga, yaitu: a. Luas lahan yang digunakan untuk membangun TPS 3R minimal $200 \mathrm{~m}^{2}$.

b. TPS 3R dilengkapi dengan ruang pemilahan, pengomposan sampah organik, dan/atau unit penghasil biogas, gudang, zona penyangga, dan tidak mengganggu estetika dan lalu lintas.

c. Lokasi TPS 3R ditempatkan sedekat mungkin dengan daerah pelayanan, dalam radius tidak lebih dari $1 \mathrm{~km}$.

d. Lokasinya mudah diakses.

e. Memiliki jadwal pengumpulan dan pengangkutan.

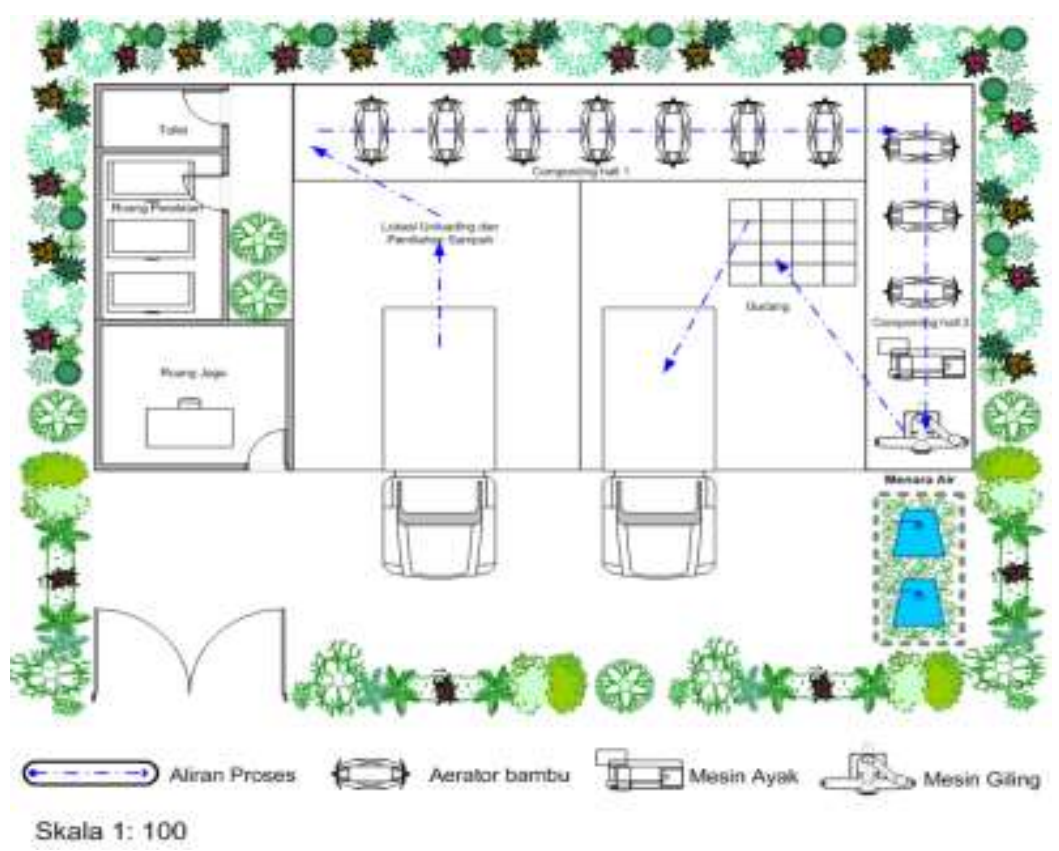

Gambar 1

Contoh Denah TPS 3R (KPUPR, 2017)

Berdasarkan Petunjuk Teknis TPS 3R Dirjen Cipta Karya KPUPR, desain minimal bangunan TPS 3R memuat beberapa area dan sarana, yaitu: (1) area penerimaan (dropping area); (2) area pemilahan; (3) area pencacahan dan mesin pencacah; (4) area komposting; (5) area pematangan kompos/angina; (6) gudang kompos dan lapak serta tempat residu; (7) kantor; dan (8) sarana air bersih dan sanitasi. Contoh denah sederhana dapat dilihat pada Gambar 1.

\subsection{Tingkat Partisipasi Produsen Warung Makan}

Gambar 1 menunjukkan bahwa seluruh responden produsen warung makan setuju jika TPS 3R diselenggarakan di Desa Babakan. Responden produsen warung makan mengetahui dan menyadari sebagian sampah yang dihasilkan di warung makan masih dapat diolah dan dimanfaatkan, namun tidak bisa melakukan pengolahan sampah secara mandiri (individual) karena terbatasnya luas lahan warung makan, waktu, dan tenaga yang dimiliki sehingga membutuhkan pihak lain untuk melakukannya. Pengolahan sampah warung makan pada skala komunal dengan 
TPS 3R dapat menjadi upaya pengelolaan sampah dengan konsep 3R. Tersedianya infrastruktur pengolahan sampah TPS 3R diharapkan dapat meningkatkan partisipasi produsen warung makan untuk memilah sampah dari sumbernya.

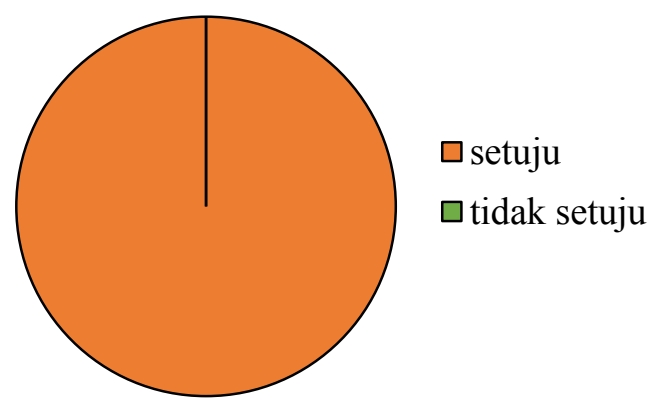

Gambar 2.

Persepsi Terhadap Rencana Penyelenggaraan TPS 3R di Desa Babakan

Partisipasi langsung dalam konteks pengelolaan sampah berupa memilah sampah organik dan anorganik dalam proses pewadahan (Yolarita, 2011 dalam Nugraha et al.,2018), sedangkan partisipasi tidak langsung adalah keterlibatan masyarakat dalam hal keuangan, yaitu membayar retribusi layanan sampah (Yuliastuti et al.,2013 dalam Nugraha et al.,2018). Gambar 2 menunjukkan bahwa sebagian besar responden bersedia memilah dan membayar retribusi kebersihan jika TPS 3R diselenggarakan di Desa Babakan (42,31\%), artinya keberadaan fasilitas TPS 3R dapat memacu masyarakat untuk terlibat dalam pengelolaan sampah baik secara langsung (memilah sampah) dan tidak langsung (membayar retribusi). Hal ini disebabkan karena keberadaan fasilitas yang memadai dapat memengaruhi respon dan partisipasi masyarakat dalam pengelolaan sampah dan kebersihan lingkungan (Amasuomo et al., 2015). Meskipun demikian, responden menganggap produsen warung makan dapat memilah sampah mandiri secara berkelanjutan jika ada peraturan yang jelas dan tegas. Hal ini disebabkan proses memilah sampah di warung makan dapat mengurangi efektivitas dan kecepatan bekerja sehingga akan ada kemungkinan untuk enggan melakukannya, terutama pada saat ramai pengunjung. Menurut Dhokhikah et al. (2015), ditegakkannya peraturan dari pihak yang berwenang dapat mendorong masyarakat untuk memilah sampahnya secara mandiri.

Namun, meskipun demikian, masih ada responden produsen warung makan yang tidak bersedia berpartisipasi baik memilah sampah dan membayar retribusi meskipun setuju jika TPS 3R diselenggarakan di Desa Babakan (15.38\%). Alasan yang mendasari ketidaksediaan responden untuk memilah sampah dari sumbernya adalah (1) mengurangi kecepatan dan keefektifan bekerja terutama pada saat jam ramai pengunjung; (2) sumberdaya manusia (SDM) belum mendukung dan jumlahnya terbatas. Sedangkan alasan yang mendasari ketidaksediaan untuk membayar retribusi adalah: (1) menganggap masalah sampah seharusnya ditangani serta dikelola oleh pemerintah setempat dan bukan dibebankan kepada masyarakat; (2) biaya retribusi kebersihan yang dibayarkan saat ini sudah membebani biaya operasional warung makan. Masih adanya produsen warung makan yang tidak bersedia baik memilah sampah maupun membayar retribusi sangat berpotensi adanya free rider dalam pengelolaan sampah warung makan di Desa Babakan. Keberadaan free rider ini dapat menyebabkan aksi lingkungan kolektif gagal untuk diinisiasi atau dijalankan (Yau, 2010). Insentif ekonomi adalah cara paling efektif untuk mengatasi free rider dalam pengelolaan sampah di masyarakat (Xu et al.,2018).Selain itu penetapan nilai retribusi pengelolaan sampah yang dapat diterima oleh seluruh masyarakat juga dapat menjadi cara untuk mengatasi free rider dalam pengelolaan sampah (Banga et al.,2011). 


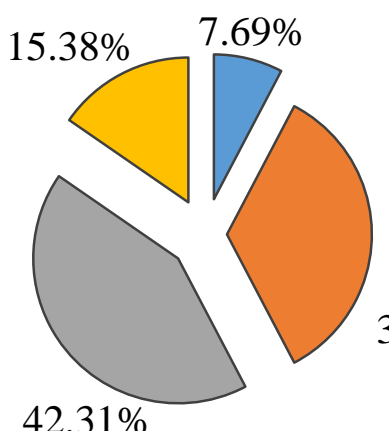

$\square$ Memilah saja

$\square$ Retribusi saja

$\square$ Memilah dan

Retribusi

$\square$ Tidak keduanya

$34.62 \%$

Gambar 3

Partisipasi Produsen Warung Makan

Terhadap Rencana Penyelenggaraan TPS 3R
3.3 Willingness to Pay Produsen Warung Makan terhadap Penyelenggaraan TPS 3R

Kesediaan atau ketidaksediaan responden produsen warung makan untuk membayar retribusi kebersihan terkait rencana penyelenggaraan TPS 3R dapat dilihat pada Tabel 2. Tabel 2 menunjukkan bahwa tidak semua responden bersedia untuk membayar retribusi untuk rencana penyelenggaraan TPS 3R di Desa Babakan, yaitu 16,67\%. Responden produsen A la Carte yang tidak bersedia membayar retribusi yang lebih banyak untuk pengelolaan TPS 3R lebih banyak dibandingkan dengan responden produsen Warteg.

Tabel 2. Kesediaan Membayar Responden Terhadap Rencana Penyelenggaraan TPS 3R

\begin{tabular}{lccccc}
\hline \multirow{2}{*}{ Responden } & Total & \multicolumn{4}{c}{ Kesediaan } \\
\cline { 3 - 6 } & & \multicolumn{2}{c}{ Bersedia } & \multicolumn{2}{c}{ Tidak bersedia } \\
\cline { 3 - 6 } & & $\begin{array}{c}\text { Jumlah } \\
\text { (orang) }\end{array}$ & Persentase $(\%)$ & $\begin{array}{l}\text { Jumlah } \\
\text { (orang) }\end{array}$ & Persentase (\%) \\
\hline Warteg & 11 & 10 & 90.91 & 1 & 9.09 \\
\hline A la Carte & 13 & 10 & 76.92 & 3 & 23.08 \\
\hline Total & 24 & 20 & 83.33 & 4 & 16.67 \\
\hline
\end{tabular}

Setelah dilakukan dua tahapan utama dalam CVM yaitu konstruksi skenario hipotetik dan penawaran nilai WTP, maka tahap selanjutnya yang dilakukan adalah menduga rataan nilai WTP (EWTP) responden produsen warung makan terhadap rencana penyelenggaraan TPS $3 R$ di Desa
Babakan. Hasil penawaran nilai WTP dan rataan nilai WTP produsen Warteg dan A la Carte terhadap rencana penyelenggaraan TPS 3R di Desa Babakan dijabarkan pada Tabel 3. Tabel 3 menunjukkan nilai rataan WTP produsen Warteg lebih tinggi dibandingkan dengan nilai rataan WTP produsen A la Carte.

Tabel 3. Distribusi Rataan NIlai WTP Produsen Warung Makan

\begin{tabular}{ccccc}
\hline Jenis warung makan & $\begin{array}{c}\text { Nilai WTP } \\
\text { (Rp/orang) }\end{array}$ & $\begin{array}{c}\text { Jumlah } \\
\text { Responden } \\
\text { (orang) }\end{array}$ & $\begin{array}{c}\text { Jumlah Nilai } \\
\text { WTP }\end{array}$ & $\begin{array}{c}\text { EWTP } \\
\text { (Rp/bulan) }\end{array}$ \\
\hline & 10.000 & 1 & 10.000 & \\
& 12.500 & 1 & 12.500 & \\
Warung Tegal & 15.000 & 1 & 15.000 & \\
& 20.000 & 2 & 40.000 & \multirow{2}{*}{35.000} \\
& 30.000 & 1 & 30.000 & \\
& 32.500 & 1 & 32.500 & \\
& 50.000 & 1 & 50.000 & \\
& 60.000 & 1 & 60.000 & \\
& 100.000 & 1 & 100.000 & \\
\hline
\end{tabular}




\begin{tabular}{|c|c|c|c|c|}
\hline Jenis warung makan & $\begin{array}{l}\text { Nilai WTP } \\
\text { (Rp/orang) }\end{array}$ & $\begin{array}{c}\text { Jumlah } \\
\text { Responden } \\
\text { (orang) }\end{array}$ & $\begin{array}{c}\text { Jumlah Nilai } \\
\text { WTP }\end{array}$ & $\begin{array}{c}\text { EWTP } \\
\text { (Rp/bulan) }\end{array}$ \\
\hline \multirow{5}{*}{ A la Carte } & 15.000 & 1 & 15.000 & \multirow{5}{*}{29.500} \\
\hline & 20.000 & 2 & 40.000 & \\
\hline & 25.000 & 2 & 50.000 & \\
\hline & 30.000 & 3 & 90.000 & \\
\hline & 50.000 & 2 & 100.000 & \\
\hline Total & & 17 & 295.000 & \\
\hline Total EWTP & & 27 & 865,000 & 32.250 \\
\hline
\end{tabular}

Warung Tegal memiliki kemampuan membayar yang tinggi dibandingkan dengan A la Carte dan hal ini dapat dilihat dari nilai bid yang diberikan untuk rencana penyelenggaraan TPS 3R di Desa Babakan, yaitu mencapai Rp 100,000.00 sehingga nilai EWTP yang didapatkan pun tinggi.Selain itu, rataan nilai WTP produsen $A$ la Carte yang lebih rendah dibandingkan rataan nilai WTP Warteg diduga karena:

\subsubsection{Luas Bangunan}

Bangunan A la Carte di Desa Babakan cenderung lebih luas dibandingkan dengan Warteg. Hal ini menyebabkan biaya sewa dan operasional (terutama pembayaran listrik) $A$ la Carte lebih tinggi dibandingkan Warteg sehingga nilai WTP yang diberikan oleh produsen $A$ la Carte lebih rendah dibandingkan dengan Warteg.

\subsubsection{Menu dan Frekuensi Memasak}

Menu yang tersedia di A la Carte lebih banyak dan beragam dibandingkan dengan Warteg. Selain itu, sistem penyajian $A$ la Carte dan Warteg berbeda dengan Warteg, dimana pada A la Carte makanan dimasak setelah dipesan oleh konsumen sehingga frekuensi memasak $A$ la Carte lebih banyak dibandingkan dengan Warteg yang memiliki menunya lebih terbatas dan frekuensi memasaknya lebih sedikit. Jumlah menu dan frekuensi memasak A la Carte yang lebih banyak menyebabkan biaya yang digunakan untuk membeli bahan dan operasional untuk memasak menjadi lebih tinggi sehingga nilai WTP yang diberikan untuk pengelolaan sampah lebih rendah dibandingkan dengan Warteg.

\subsubsection{Jumlah Pegawai}

Bangunan yang lebih luas, jumlah menu serta frekuensi memasak yang lebih banyak pada $A$ la Carte menyebabkan jumlah pegawai yang dipekerjakan lebih banyak dibandingkan dengan Warteg yang umumnya hanya memiliki 1-2 orang pegawai. Warung $A$ la Carte di Desa Babakan sebagian besar memiliki setidaknya 3 atau lebih orang pegawai sehingga biaya yang dikeluarkan untuk pegawai lebih tinggi dibandingkan dengan Warteg. Hal ini menyebabkan nilai WTP yang diberikan oleh produsen $A$ la Carte lebih rendah dibandingkan dengan produsen Warteg.

Nilai EWTP secara keseluruhan responden warung makan adalah $\mathrm{Rp}$ 32.250/bulan. Setelah diperoleh nilai EWTP, kemudian dihitung nilai total WTP berdasarkan data distribusi WTP responden yang juga merupakan estimasi penerimaan terhadap rencana penyelenggaraan TPS $3 \mathrm{R}$ di Desa Babakan. Tabel 4 menunjukkan estimasi penerimaan per tahun yang diperoleh dari nilai WTP produsen Warteg dan A la Carte adalah $\mathrm{Rp}$ 9.288.000.

Tabel 4 Estimasi Penerimaan dari Nilai WTP Produsen Warung Makan

\begin{tabular}{cccc}
\hline $\begin{array}{c}\text { WTP } \\
\text { Responden } \\
\text { (Rp/bulan) }\end{array}$ & $\begin{array}{c}\text { Jumlah } \\
\text { populasi }\end{array}$ & $\begin{array}{c}\text { Estimasi } \\
\text { penerimaan } \\
\text { (Rp/bulan) }\end{array}$ & $\begin{array}{c}\text { Estimasi } \\
\text { penerimaan } \\
\text { (Rp/tahun) }\end{array}$ \\
\hline 32.250 & 24 & 774.000 & 9.288 .000
\end{tabular}

Rataan nilai WTP lebih tinggi dibandingkan dengan rataan retribusi pengangkutan sampah yang berlaku saat ini, yaitu Rp 18.750/bulan (Tabel 5). Rataan nilai 
WTP untuk TPS 3R yang lebih tinggi dari rataan nilai retribusi pengangkutan sampah saat ini mengindikasikan bahwa baik produsen Warteg dan A la Carte memiliki kepedulian untuk memperbaiki sistem pengelolaan sampah di Desa Babakan yang ada saat ini dan hal ini sejalan dengan pembahasan sebelumnya yang dimana sebagian besar responden produsen warung makan memiliki tingkat partisipasi untuk membayar retribusi yang tinggi. Namun, rencana penyelenggaraan TPS 3R di Desa Babakan tidak hanya membutuhkan partisipasi dari produsen warung makan saja, tetapi juga dari pelaku usaha jenis lainnya serta rumah tangga karena kapasitas TPS 3R minimal $400 \mathrm{KK}$ (KPUPR, 2017) dan dalam penelitian ini hanya mengkaji tingkat partisipasi dari pelaku usaha Warteg dan A la Carte di Desa Babakan.

Tabel 5 Distribusi Retribusi Kebersihan Saat Ini

\begin{tabular}{cccc}
\hline $\begin{array}{c}\text { Retribusi } \\
\text { saat ini } \\
\text { (Rp/orang) }\end{array}$ & $\begin{array}{c}\text { Jumlah } \\
\text { Responden } \\
\text { (orang) }\end{array}$ & $\begin{array}{c}\text { Jumlah } \\
\text { Nilai } \\
\text { Retribusi }\end{array}$ & $\begin{array}{c}\text { Jumlah } \\
\text { Nilai } \\
\text { Retribusi }\end{array}$ \\
\hline 10.000 & 8 & 80.000 & \\
15.000 & 2 & 30.000 & \\
20.000 & 5 & 100.000 & 35.000 \\
25.000 & 3 & 75.000 & \\
40.000 & 1 & 40.000 & \\
50.000 & 1 & 50.000 & \\
\hline
\end{tabular}

\section{SIMPULAN DAN SARAN}

\subsection{Simpulan}

1. Tingkat partisipasi produsen warung makan terhdap rencana penyelenggaraan TPS 3R sudah cukup baik, meskipun masih ada potensi free rider karena masih ada produsen warung makan yang tidak bersedia untuk berpartisipasi sama sekali sehingga dapat menjadi tantangan bagi rencana penyelenggaraan TPS $3 R$ di Desa Babakan.

2. Rataan nilai WTP adalah $\mathrm{Rp}$ 32.250/bulan sehingga estimasi penerimaan berdasarkan WTP tersebut adalah Rp 9.288.000/tahun. Rataan nilai WTP lebih tinggi dibandingkan dengan rataan nilai retribusi kebersihan saat ini.

\subsection{Saran}

Sosialisasi atau kampanye terkait manfaat dan pentingnya pengelolaan sampah dengan TPS 3R harus dilakukan oleh pihak-pihak terkait agar informasi mengenai TPS 3R dapat diterima oleh seluruh lapisan masyarakat di Desa Babakan sehingga potensi free rider dapat diatasi dan sistem pengelolaan sampah kumpul-angkut-buang yang ada saat ini dapat ditinggalkan. Perlu dilakukan penelitian lebih lanjut terkait implementasi pengelolaan sampah dengan sistem TPS 3R, khususnya mengenai WTP dari masyarakat pelaku usaha lain serta rumah tangga di Desa Babakan karena TPS 3R memiliki kapasitas minimal 400KK sedangkan populasi dalam penelitian ini hanya 33 warung makan.

\section{DAFTAR PUSTAKA}

Amasuomo, E., Tuoyo, O.J.A., Hasnain, S.A. Analysis of public participation in sustainable waste management practice in Abuja, Nigeria. Environ Manag and Sustain Developm. 4(1):180-193. http://dx.doi.org/10.5296/emsd.v4i1.7269

Anjani, A. 2011. Household Waste Management in Indonesia: What Is An Effective Means to Household Waste Reduction in Indonesia? (thesis). Tokyo: Tohoku University.

Banga, M., Lokina, R.B., Mkenda, A.F. Households' willingness to pay for improved solid waste collection services in Kampala City, Uganda. $J$ of Environ \&Develop. 20(4): 428-448. doi: $10.1177 / 1070496511426779$.

Dhokhikah, Y., Trihadiningrum, Y., Sunaryo, S. 2015. Community participation in household solid waste reduction in Surabaya, Indonesia. Resources, Conservation, and Recycle.

102(2015): $153-162$. http://dx.doi.org/10.1016/j.resconrec.201 5.06.013. 
Fauzi, A. 2006. Ekonomi Sumberdaya Alam dan Lingkungan: Teori dan Aplikasi. Jakarta: Gramedia Pustaka Utama.

Fauzi, A. 2014. Valuasi Ekonomi dan Penilaian Kerusakan Sumberdaya Alam dan Lingkungan. Bogor: IPB Press.

[KPUPR]-Kementerian Pekerjaan Umum dan Perumahan Rakyat. 2015. Pengembangan Pengelolaan Persampahan. Katalog Kementerian Pekerjaan Umum dan Perumahan Rakyat Direktorat Jenderal Cipta Karya.

[KPUPR]-Kementerian Pekerjaan Umum dan Perumahan Rakyat. 2017. Petunjuk Teknis TPS 3R. Katalog Kementerian Pekerjaan Umum dan Perumahan Rakyat Direktorat Jenderal Cipta Karya.

Juanda (2004).Analisis Karakteristik Usaha Warung Tegal di Kebayoran Baru Jakart Selatan dan Implikasinya terhadap Pemberian Kredit Mikro pada PT Bank BNI (thesis). Bogor: Sekolah Pascasarjana Institut Pertanian Bogor.

Khamdevi, M. 2017.Studi karakteristik arsitektur khas pada Rumah Makan Padang di tanah rantau.J Ilmu Penelitian. 1(1):33-38.

Khamdevi, M., Nasution, I.R. 2014.Studi karakteristik khas pada Warung Tegal di Jabodetabek.J Arsitektur Univ Bandar Lampung. 4(2):1-9.

Martinawati, Zahri, I., Faizal, M. 2016. Partisipasi masyarakat dalam pengelolaan sampah rumah tangga: sebuah studi di Kecamatan Sukarami Kota Palembang. J P Sains. 18(1):14-21.

Nugraha, A., Sutjahjo, S.H, Amin, A.A. 2018 Persepsi dan partisipasi masyarakat terhadap pengelolaan sampah rumah tangga melalui bank sampah di Jakarta Selatan. J PSL. 8(1):7-14. doi: 10.29244/jps1.8.1.7-14.

Peraturan Daerah Kabupaten Bogor No.2 Tahun 2014 tentang Pengelolaan Sampah.

Peraturan Pemerintah No.81 Tahun 2012 tentang Pengelolaan Sampah Rumah
Tangga dan Sampah Sejenis Sampah Rumah Tangga.

Putra, R.I.S., Putro, S. 2015. Pengaruh karakteristik demografi dan sosial ekonomi terhadap remitansi pedagang warung makan Tegal di kawasan sekitar Universitas Negeri Semarang.Geo Image. 4(1):1-7.

Rahim I.R., Nakayama, H, Shimaoka, T. 2012. Cost analysis of municipal solid waste management in Indonesian cities. Journal of Japan Society of Civil Engineers Ser G. (Environemntal Research). 68(6):79-88.

Rahman, A. 2013. Perilaku masyarakat dalam pengelolaan sampah rumah tangga (studi kasus di Kelurahan Pasar Sarolangun). Jurnal Bina Praja. 5(4):215-220.

Subhadarsini, S. 2015. Valuation of environment: a study on willingness to pay for improved solid waste management in Paradip Town, Odisha Economic. International Jurnal of Human and Social Science Invention.4(1): 92-101.

Sugiyono. 2013. Metode Penelitian Pendidikan Pendekatan Kuantitatif, Kualitatif, dan R\&D. Bandung: Alfabeta.

Sukmadinata, N.S. 2011. Metode Penelitian Pendidikan. Bandung: Remaja Rosadakarya.

Suryantika, L., Dewi, R. 2012. Kajian komposisi gizi pada menu vegan $a$ 'la cartedi Loving Hut Restaurant Vegan Food Surabaya. J Tata Boga. 2(2):8-14.

Suyanto, E., Soetarto, E., Sumardjo, Hardjomidjodjo, H. 2015. Model kebijakan pengelolaan sampah berbasis partisipasi "green community" mendukung kota hijau. Mimbar. 31(1): 143-152.

Undang-Undang No.8 Tahun 2008 tentang Pengelolaan Sampah.

Widiarti, I.W. 2012. Pengelolaan sampah berbasis "zero waste" skala rumah tangga secara mandiri. J Sains Teknol Lingk. 4(2): 101-113. 
Xu, L., Ling, M., Wu, Y.. 2018. Economic incentive and social influence to overcome household separation dilemma: a field intervention study. Waste Manag. 77:522-531.

Yau, Y. 2010. Domestic waste recycling, collective action and economic incentive: the case in Hongkong. Waste Manag. 30(2010):2440-2447.

Diakses pada tanggal 10 Juni 2019 pada halaman http://bogorkab.go.id/. 